\title{
Rapid thyroid nodule growth is not a marker for well-differentiated thyroid cancer
}

\author{
Claudius Falch ${ }^{1}$, Steffen Axt ${ }^{1}$, Bettina Scuffi ${ }^{2}$, Alfred Koenigsrainer ${ }^{1}$, Andreas Kirschniak ${ }^{1}$ and Sven Muller ${ }^{1 *}$
}

\begin{abstract}
Background: Rapid growth of thyroid nodules is described as being associated with thyroid cancer. The objective of the study was to determine how the growth rate of thyroid nodules during follow-up is associated with the risk of thyroid cancer.

Methods: Retrospective analysis of patients undergoing thyroid surgery for nodular disease and a repetitive preoperative ultrasound work-up of at least 6 months was done. Nodule growth was considered relevant when a volume increase $>49 \%$ was detected. Growth patterns were described as rapid for a volume increase present over 6 to 24 months.

Results: Of the 297 analysed patients, 226 (76\%) displayed relevant nodule growth and 71 (24\%) no relevant growth. A rapid growth pattern was seen in 73 patients (32\%). Well-differentiated thyroid cancer was diagnosed in 33 patients (11\%; 27 papillary, 6 follicular) with a relevant nodule growth in 2 and no relevant growth in 31 patients. No rapid growth pattern was observed in any case of well-differentiated thyroid cancer. A rapid growth pattern occurred only in benign nodules (70 patients) and in 1 patient each with a lymphoma, a metastasis of a renal cell cancer and a metastasis of a gastric adenocarcinoma. Therapy with levothyroxine and/or iodine was administered to 129 patients (43\%) and was significantly inversely correlated with nodule growth (odds ratio 0.27 ; Cl $95 \% 0.14-0.53, p<0.001)$.

Conclusions: Thyroid nodule growth alone and especially a rapid growth pattern during follow-up for thyroid nodular disease is not a marker for well-differentiated thyroid cancer and should not be used as a stand-alone argument for thyroid surgery.
\end{abstract}

Keywords: Well-differentiated thyroid cancer, Thyroid nodule, Growth

\section{Background}

Thyroid nodules are frequently detected during neck ultrasound. Their incidence is described in up to $50 \%$ of patients, depending on age and regional iodine intake [1]. Compared with this rate, the incidence of thyroid malignancy is rare [2]. However, because of the probability of malignancy in any thyroid nodule, ultrasound work-up is recommended [3]. Sonographic features suspicious for malignancy are internal calcification, hypoechogenity, centrally increased blood flow,

\footnotetext{
* Correspondence: Sven.mueller@med.uni-tuebingen.de

'Department for Visceral, General and Transplant Surgery, Tuebingen

University Hospital, Waldhoernlestrasse 22, 72076 Tuebingen, Germany

Full list of author information is available at the end of the article
}

infiltrative margins and a nodule taller than wider [4]. Thyroid nodule growth alone is not believed to be a sign of malignancy, but rapid nodule growth is described as being associated with thyroid cancer $[5,6]$. The 2009 American Thyroid Association guidelines suggest that a $50 \%$ threshold for nodule volume increase at follow-up US is a criterion for further diagnostic work-up to rule out malignancy [7]. Growth occurs over time in benign thyroid nodules in 20 to $39 \%$ of patients, depending on whether levothyroxine and/or iodine is administered or not [8, 9]. Hence, one is regularly confronted with this problem during follow-up for thyroid nodules, and the definition of substantial nodule growth remains unclear. 
Therefore, we aimed to investigate growth patterns of thyroid nodules during preoperative work-up and their correlation with well-differentiated thyroid malignancy.

\section{Methods}

A series of 1209 consecutive patients undergoing thyroid resection at Tuebingen University Hospital from January 2005 to December 2013 was retrospectively analysed using our electronic patient database. All patients with a thyroid resection for nodular disease and a preoperative repetitive ultrasound work-up of at least 6 months were included in the analysis. The main outcome measure was the correlation of nodule growth and the final histopathologic diagnosis.

Patients with incomplete sonographic documentation of the width, depth and length of the thyroid nodule as well as complete cystic lesions were excluded. The following parameters were assessed: age, gender, uninodular or multinodular thyroid, final histopathologic diagnosis and preoperative therapy with levothyroxine and/ or iodine. Furthermore, change in sonographic nodule characteristics as microcalcification, hypoechogenity and irregular nodule margins during follow-up were recorded. Fine needle aspiration biopsy (FNAB) was not performed routinely in the diagnostic work-up process for thyroid nodules and thus was not further analysed because of low availability in this series. According to the final histopathologic examination, underlying thyroid disease diagnosis was classified as benign nodular thyroid disease (uninodular or multinodular) and primary or secondary thyroid cancer. All thyroid specimens were evaluated histologically by a board-certified pathologist.

Thyroid nodule volume was retrospectively estimated according to Brauer et al. using the maximal width, depth and length of the nodule for calculation with the rotation ellipsoid formula: ${ }^{V}$ ellipsoid $\pi^{16}{ }^{*}{ }^{2}$ length ${ }^{*} D$ width ${ }^{*} D$ depth. Only an increase in the nodule volume $>49 \%$ was interpreted as a relevant nodule growth, while lesser volume changes were classified as no relevant nodule change [10]. Nodule growth pattern was further subclassified as rapid nodule growth if the nodule volume increased within 6 to 24 months. Data were analysed by using statistical software, SPSS, version 21.0.0.1 (SPSS Inc., Chicago, IL, USA). As statistical tests, the Fisher exact test, the chi-square test and Kruskal-Wallis test were used where appropriate. A $p$ value of less than 0.05 was considered statistically significant. Multiple logistic regression analysis was performed to investigate the influence of confounders in determining independent variables for nodule growth (age, gender, type of nodularity, levothyroxine therapy, final pathology, initial thyroid nodule volume, follow-up duration) and for welldifferentiated thyroid cancer (age, gender, type of nodularity, growth pattern, initial thyroid nodule volume, final thyroid nodule volume, follow-up duration, change in sonographic characteristics). The study was conducted in accordance with the ethical requirements regarding the protection of the rights and welfare of human subjects participating in medical research (Ethical Review Board of the University of Tuebingen, Germany).

\section{Results}

Of 1209 patients with a thyroid resection, 368 patients had a repetitive preoperative ultrasound work-up of at least 6 months. A complete record of thyroid nodule dimensions was available in 297 (25\%) patients and was included in the final analysis. The incidence of thyroid malignancy in the overall population was 159 (13.2\%) out of 1209 patients.

Of the 297 patients ultimately analysed, 226 (76\%) displayed relevant nodule growth and 71 (24\%) no relevant growth. A rapid nodule growth pattern ( $<24$ months) was seen in 73 (32\%) of the patients with relevant nodule growth, whereas the remaining 153 patients showed moderate growth ( $>24$ months). Details and characteristics of patients according to their thyroid nodule growth patterns are displayed in Table 1. Thyroid nodule growth as sole criterion for surgery was present in 137 (46\%) patients, while local symptoms led to surgery in 58 patients $(20 \%)$ and suspicious ultrasound features in $32(11 \%)$ patients.

Thyroid malignancy occurred in 37 (12.5\%) of 297 patients, 33 of whom had a well-differentiated thyroid cancer and 4 secondary thyroid malignancies $(2$ with a metastasis of a renal cell carcinoma, 1 non-Hodgkin's lymphoma and 1 metastasis of an adenocarcinoma of the stomach). No case of undifferentiated or medullary thyroid cancer occurred in the series. In two patients with well-differentiated thyroid cancer, lymphatic micrometastases were confirmed in the central compartment, while no gross lymphatic metastatic involvement was observed in any patient. Twenty cases of well-differentiated thyroid cancer were diagnosed in multinodular thyroid disease. Twelve of these were manifested in the dominant nodule on ultrasound, while 6 of the remaining 8 cases proved to be incidental papillary microcarcinoma.

The initial mean nodule volume was comparable for nodules with relevant rapid growth $\left(2.62 \pm 0.96 \mathrm{~cm}^{3}\right)$, with relevant moderate growth $\left(2.3 \pm 1.31 \mathrm{~cm}^{3}\right)$ and no growth $\left(2.47 \pm 1.29 \mathrm{~cm}^{3} ; p=0.657\right)$. Mean volume increased to $4.34 \pm 1.69 \mathrm{~cm}^{3}$ for nodules with relevant rapid growth, to $5.97 \pm 3.78 \mathrm{~cm}^{3}$ for nodules with relevant moderate growth and to $3.26 \pm 2.65 \mathrm{~cm}^{3}$ for those with no growth following a median follow-up period of 13 (range 6-24), 41 (range 25-79) and 24 (range 6-89) months, respectively. Patients with relevant thyroid 
Table 1 Characteristics of the study population with followed-up thyroid nodules displaying a rapid nodule growth (increase in nodule volume over 50 \% within 24 months), moderate nodule growth (increase in nodule volume over 50 \% and over 24 months) and no relevant nodule growth

\begin{tabular}{|c|c|c|c|c|}
\hline & \multicolumn{2}{|l|}{ Relevant nodule growth } & \multirow{2}{*}{$\begin{array}{l}\text { No nodule } \\
\text { growth }\end{array}$} & \multirow[t]{2}{*}{$p$ value } \\
\hline & $\begin{array}{l}\text { Rapid nodule growth } \\
<24 \text { months }\end{array}$ & $\begin{array}{l}\text { Moderate nodule growth } \\
>24 \text { months }\end{array}$ & & \\
\hline No. of patients $(n)$ & $73(\%)$ & $153(\%)$ & $71(24 \%)$ & \\
\hline Gender (female, $n$ ) & $48(66 \%)^{\mathrm{a}}$ & $115(75 \%)^{a}$ & $46(65 \%)^{a}$ & 0.317 \\
\hline Median age at surgery, [range] & $48[19-81]$ & $54[16-84]$ & $49[17-78]$ & 0.476 \\
\hline \multicolumn{5}{|l|}{ Nodularity } \\
\hline Uninodular & $11(15 \%)$ & $20(13 \%)$ & $20(28 \%)$ & \multirow[t]{2}{*}{0.019} \\
\hline Multinodular & $62(85 \%)$ & $133(87 \%)$ & $51(72 \%)$ & \\
\hline Median follow-up duration, months [range] & $13[6-24]$ & $41[25-79]$ & $24[6-89]$ & \\
\hline Initial mean thyroid nodule volume $\left(\mathrm{cm}^{3}\right)$ & $2.62 \pm 0.96$ & $2.3 \pm 1.31$ & $2.47 \pm 1.29$ & 0.598 \\
\hline Final mean thyroid nodule volume $\left(\mathrm{cm}^{3}\right)$ & $4.34 \pm 1.69$ & $5.97 \pm 3.78$ & $3.26 \pm 2.65$ & \multirow[t]{3}{*}{$<0.001$} \\
\hline Benign disease $(n)$ & $70(96 \%)^{\mathrm{a}}$ & $149(97 \%)^{a}$ & $41(58 \%)^{a}$ & \\
\hline Malignant disease $(n)$ & $3(\%)^{a}$ & $4(\%)^{a}$ & $30(42 \%)^{a}$ & \\
\hline Papillary thyroid cancer $(>1 \mathrm{~cm})$ & 0 & 0 & 11 & \\
\hline Papillary microcarcinoma $(<1 \mathrm{~cm})$ & 0 & 2 & 14 & \multirow[t]{3}{*}{$<0.001$} \\
\hline Follicular thyroid cancer & 0 & 1 & 5 & \\
\hline Secondary thyroid malignancy & 3 & 1 & 0 & \\
\hline Therapy with levothyroxine and/or iodine $e^{a}$ & $17(23 \%)^{a}$ & $66(43 \%)^{a}$ & $46(65 \%)^{a}$ & $<0.023$ \\
\hline
\end{tabular}

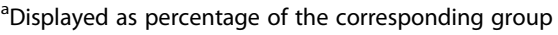

nodule growth had significantly less frequently undergone therapy with levothyroxine and/or iodine as compared to patients with no relevant growth. In a multiple logistic regression analysis, only therapy with levothyroxine and/or iodine was significantly inversely correlated with thyroid nodule growth (odds ratio 0.28; CI $95 \% 0.142-0.539, p<0.001$ ).

Well-differentiated thyroid cancer occurred significantly more often in patients with no relevant nodule growth than in patients with relevant nodule growth. A rapid growth pattern was not observed in any patient with well-differentiated thyroid cancer, but in 3 patients with secondary thyroid malignancies (1 patient each with a lymphoma, a metastasis of a renal cell cancer and a metastasis of a gastric adenocarcinoma), 13 with benign uninodular disease and 57 with benign multinodular disease. Levothyroxine and/or iodine therapy was not correlated with nodule dignity.

Thyroid nodule characteristics according to their histopathologic findings are displayed in Table 2. Multivariate analysis revealed only uninodularity (odds ratio 3.59; CI $95 \% 1.36-9.52, p=0.01$ ) predictive for welldifferentiated thyroid cancer. An inverse correlation was observed for nodule growth pattern, predicting welldifferentiated thyroid cancer (odds ratio 0.11; CI $95 \%$ $0.05-0.23, p>0.001)$. Changes in sonographic nodule characteristics such as microcalcification, hypoechogenity and irregular nodule margins during follow-up were observed slightly more frequent in thyroid malignancies than in benign findings, but lack significance due to their rare appearance in multivariate analysis.

\section{Discussion}

Natural growth behaviour of thyroid nodules is controversially discussed. Reports of volume change in thyroid nodules over time vary from largely decreasing [11-13] to predominantly increasing $[8,9]$, depending on factors such as type of nodularity (uninodular vs. multinodular) [14], iodine deficiency [15], anatomic configuration of the nodule (cystic content) [6] and administration of therapy with levothyroxine [16]. Most recently, Durante et al. described a volume increase of asymptomatic and sonographic unsuspicious nodules in only $15 \%$ over 5 years [17]. According to our results, they found a low incidence of thyroid cancer and no association with nodule growth. Furthermore, there is no clear consensus on how to define substantial thyroid nodule growth [3]. Brauer et al. reported a relevant interobserver variation in thyroid nodule volume measurement when the nodule volume change was reported to be below $50 \%$, resulting in conflicting interpretations [10]. They thus recommended that a nodule volume change of at least $49 \%$ or more should be interpreted only as relevant nodule shrinkage or growth [10]. Thyroid nodule 
Table 2 Thyroid nodule characteristics according to their histopathologic findings; $p$ value displayed as well-differentiated thyroid cancer vs. benign findings

\begin{tabular}{|c|c|c|c|c|c|c|c|}
\hline \multirow[b]{3}{*}{ N } & \multirow{3}{*}{$\begin{array}{l}\text { Benign } \\
260\end{array}$} & \multicolumn{3}{|c|}{ Well differentiated thyroid cancer } & \multirow{3}{*}{$\begin{array}{l}\text { Secondary } \\
\text { malignancy } \\
4\end{array}$} & \multirow{3}{*}{$\begin{array}{l}\text { Malignant } \\
\text { total } \\
37\end{array}$} & \multirow[t]{3}{*}{$p$ value } \\
\hline & & \multirow{2}{*}{$\begin{array}{l}\text { Papillary } \\
27\end{array}$} & \multirow{2}{*}{$\begin{array}{l}\text { Follicular } \\
6\end{array}$} & \multirow{2}{*}{$\begin{array}{l}\text { Total } \\
33\end{array}$} & & & \\
\hline & & & & & & & \\
\hline \multicolumn{8}{|l|}{ Nodularity } \\
\hline Uninodular & $36(14 \%)$ & 12 & 1 & $13(39 \%)$ & 2 & 15 & 0.001 \\
\hline Multinodular & $224(86 \%)$ & 15 & 5 & $20(61 \%)$ & 2 & 22 & \\
\hline Initial nodule volume $>2 \mathrm{~cm}^{3}$ & $185(71 \%)$ & 10 & 5 & $15(45 \%)$ & 2 & 17 & 0.004 \\
\hline Nodule volume $>2 \mathrm{~cm}^{3}$ at last follow-up & $226(87 \%)$ & 12 & 6 & $18(55 \%)$ & 3 & 21 & 0.001 \\
\hline Median months ultrasound follow-up of nodule before surgery & $28[6-89]$ & & & $31[6-53]$ & $11[6-26]$ & & 0.001 \\
\hline \multicolumn{8}{|l|}{ Sonomorphologic change in nodule pattern } \\
\hline Hypoechogenity & $24(9 \%)$ & 5 & 1 & $6(18 \%)$ & 3 & 9 & 0.237 \\
\hline Microcalcification & $12(4.6 \%)$ & 6 & 1 & $7(21 \%)$ & 0 & 7 & 0.004 \\
\hline Taller than wide & $11(4.2 \%)$ & 3 & 2 & $5(15 \%)$ & 2 & 7 & 0.036 \\
\hline Irregular nodule margins & $5(2 \%)$ & 1 & 0 & $1(3 \%)$ & 1 & 2 & 0.553 \\
\hline Suppressive therapy with levothyroxine and/or iodine & $109(42 \%)$ & 17 & 2 & $19(58 \%)$ & 1 & 20 & 0.292 \\
\hline
\end{tabular}

growth per se seems not to be a stand-alone marker for malignancy. Kim et al. reported that nodules showing more than $50 \%$ growth during sonographic follow-up were unlikely to result in a diagnosis of malignancy, whereas malignancy was more often present when suspicious US features were found [18]. However, the revised American Thyroid Association guidelines from 2015 suggested that a $50 \%$ threshold for nodule volume increase at follow-up is a criterion for further diagnostic work-up and repeat FNA to rule out malignancy (weak recommendation based on low quality evidence) [19]. Moreover, in commonplace practice, thyroid nodules with growth are often surgically treated to rule out cancer [20]. The results of this study show that relevant thyroid nodule growth over time defined as a volume increase of more than $50 \%$ is present in three fourths of the patients followed. Moreover, rapid nodule growth within 24 months was seen in $30 \%$ of all patients. Nevertheless, nodule growth was rarely associated with well-differentiated thyroid cancer, and a rapid thyroid nodule growth pattern occurred only in benign lesions, metastatic cancers and lymphoma. All data were obtained from a surgical database, meaning that data from patients still under follow-up without surgery were not included in this analysis. These results are thus not comparable to the results of plain observational studies reporting much lower thyroid nodule growth rates $[18,21]$. In matters of nodule growth and well-differentiated thyroid cancer, this might even further increase the ratio of patients with relevant nodule growth and without thyroid malignancy.

Also, the majority of patients in this series were operated on because of relevant nodule growth without any further signs of malignancy. Only two of these mentioned patients subsequently displayed a papillary microcarcinoma in thyroid nodule under surveillance interpretable as an incidental finding without any further clinical relevance. On the other hand, patients with proven well-differentiated thyroid cancer showed no substantial nodule growth. These results are comparable with the findings made by Ajmal et al. that thyroid cancer is a very slow growing process that may not progress substantially over many years [22]. Of importance, no locally infiltrating or metastatic well-differentiated thyroid cancer was observed in the study population, which led us to conclude that the therapy concept was curative in all patients. Therefore, thyroid nodule growth as a stand-alone argument for malignancy should be abandoned.

Excluding the incidental findings of papillary microcarcinoma, 12 of 14 well-differentiated thyroid cancers diagnosed in a multinodular thyroid proved to be in the dominant nodule on ultrasound. This is in accordance with the findings made by Kunreuther et al., who reported that thyroid cancer was most often found in patients with multiple nodules in the dominant or largest nodule [23].

In addition, changes in sonographic nodule characteristics suspicious for malignancy during follow-up such as microcalcification, hypoechogenity and irregular nodule margins during follow-up were observed slightly more frequently in thyroid malignancies than in benign findings. However, these findings lacked statistical relevance mainly because patients with suspicious sonographic findings most likely underwent surgery initially, the majority of patients in this study had sonographically unsuspicious nodules in their baseline ultrasound and 
the incidence of thyroid malignancy during follow-up was too low to show a statistically significant difference. Recent observational studies have reported that sonographic nodule characteristics, and not nodule growth, are important signs in the diagnosis of malignancy [18].

Limitations of our findings are the facts that in addition to a potential bias due to its retrospective design, only patients with initially mainly unsuspicious nodules on ultrasound completed follow-up and definite histopathologic diagnoses after surgery were included. Three fourths of all patients operated during the study period were excluded from the analysis because no nodule follow-up was described or available. However, the incidence of well-differentiated thyroid cancer in the study population was comparable to that in the overall population of patients operated during the study period, indicating that this selection does not seem to have influenced cancer incidence.

Some reports have shown that FNAB during followup of thyroid nodules, especially in cystic lesions might have a short-term effect on nodule size and growth pattern, making interpretation questionable [24]. However, long-term effects of FNAB on nodule size seem to be neglectable [25]. With regard to the low number of preoperative FNAB and the exclusion of complete cystic lesions, we believe that the described alteration of nodule size due to the FNAB has no effect on our observed general conclusion.

Since rapid thyroid nodule growth might prove to be an undifferentiated thyroid cancer or secondary malignancy, correct preoperative diagnosis by means of, e.g. FNAB is of paramount importance as this might relevantly alter the treatment in most of these cases [26].

\section{Conclusions}

Altogether, thyroid nodule growth taken alone during follow-up is not a marker for well-differentiated thyroid cancer and should not be used as a stand-alone argument for thyroid surgery.

\section{Competing interests}

This manuscript contains original material that has not been published or submitted to any other journal. The authors declare no competing conflict of interest.

\section{Authors' contributions}

CF, AKi and SM designed the study, analysed the data, performed the statistical analysis and drafted the manuscript and had full access to all of the data in the study and take responsibility for the integrity of the data and the accuracy of the data analysis. SA and BS helped in the design and coordination of the study and drafted the manuscript. AK helped to draft the manuscript and analysed the data. All authors read and approved the final manuscript.

\section{Author details}

'Department for Visceral, General and Transplant Surgery, Tuebingen University Hospital, Waldhoernlestrasse 22, 72076 Tuebingen, Germany. ${ }^{2}$ Department for General and Visceral Surgery, Marienhospital, Stuttgart, Germany.

Received: 29 September 2015 Accepted: 10 December 2015

Published online: 18 December 2015

\section{References}

1. Reiners $\mathrm{C}$, Wegscheider $\mathrm{K}$, Schicha $\mathrm{H}$, et al. Prevalence of thyroid disorders in the working population of Germany: ultrasonography screening in 96,278 unselected employees. Thyroid. 2004;14(11):926-32.

2. Callender GG, Carling T, Christison-Lagay E, Udelsman R. Surgery for thyroid cancer. Endocrinol Metab Clin North Am. 2014:43(2):443-58.

3. Frates MC, Benson CB, Charboneau JW, et al. Management of thyroid nodules detected at US: Society of Radiologists in Ultrasound consensus conference statement. Ultrasound Q. 2006;22(4):231-8.

4. Brito JP, Gionfriddo MR, Al Nofal A, et al. The accuracy of thyroid nodule ultrasound to predict thyroid cancer: systematic review and meta-analysis. J Clin Endocrinol Metab. 2014;99(4):1253-63.

5. Grant CS, Hay ID, Gough IR, McCarthy PM, Goellner JR. Long-term follow-up of patients with benign thyroid fine-needle aspiration cytologic diagnoses. Surgery. 1989;106(6):980-5

6. Alexander EK, Hurwitz S, Heering JP, et al. Natural history of benign solid and cystic thyroid nodules. Ann Intern Med. 2003;138(4):315-8.

7. American Thyroid Association Guidelines Taskforce on, Thyroid N, Differentiated Thyroid C, Cooper DS, et al. Revised American Thyroid Association management guidelines for patients with thyroid nodules and differentiated thyroid cancer. Thyroid. 2009;19(11):1167-214.

8. Brander A, Viikinkoski P, Nickels J, Kivisaari L. Thyroid gland: US screening in a random adult population. Radiology. 1991;181(3):683-7.

9. Erdogan MF, Gursoy A, Erdogan G. Natural course of benign thyroid nodules in a moderately iodine-deficient area. Clin Endocrinol (Oxf). 2006; 65(6):767-71.

10. Brauer VF, Eder P, Miehle K, Wiesner TD, Hasenclever $H$, Paschke R. Interobserver variation for ultrasound determination of thyroid nodule volumes. Thyroid. 2005;15(10):1169-75.

11. Knudsen $\mathrm{N}$, Perrild H, Christiansen E, Rasmussen S, Dige-Petersen $H$, Jorgensen T. Thyroid structure and size and two-year follow-up of solitary cold thyroid nodules in an unselected population with borderline iodine deficiency. Eur J Endocrinol. 2000;142(3):224-30.

12. Kuma K, Matsuzuka F, Kobayashi A, et al. Outcome of long standing solitary thyroid nodules. World J Surg. 1992;16(4):583-7. discussion 7-8.

13. Kuma K, Matsuzuka F, Yokozawa T, Miyauchi A, Sugawara M. Fate of untreated benign thyroid nodules: results of long-term follow-up. World J Surg. 1994;18(4):495-8.

14. Laurberg $P$, Cerqueira $C$, Ovesen $L$, et al. lodine intake as a determinant of thyroid disorders in populations. Best Pract Res Clin Endocrinol Metab. 2010; 24(1):13-27.

15. Blum M, Hussain MA. Evidence and thoughts about thyroid nodules that grow after they have been identified as benign by aspiration cytology. Thyroid. 2003;13(7):637-41

16. Papini $E$, Bacci $V$, Panunzi $C$, et al. A prospective randomized trial of levothyroxine suppressive therapy for solitary thyroid nodules. Clin Endocrinol (Oxf). 1993;38(5):507-13.

17. Durante C, Costante G, Lucisano $\mathrm{G}$, et al. The natural history of benign thyroid nodules. JAMA. 2015;313(9):926-35.

18. Kim SY, Han KH, Moon HJ, Kwak JY, Chung WY, Kim EK. Thyroid nodules with benign findings at cytologic examination: results of long-term follow-up with US. Radiology. 2014;271(1):272-81.

19. Haugen BRM, Alexander EK, Bible KC, et al. 2015 American Thyroid Association Management Guidelines for Adult Patients with Thyroid Nodules and Differentiated Thyroid Cancer. Thyroid. 2015.

20. Singh Ospina N, Maraka S, Espinosa De Ycaza A, et al. Diagnostic accuracy of thyroid nodule growth to predict malignancy in thyroid nodules with benign cytology: systematic review and meta-analysis. Clin Endocrinol (Oxf). 2015.

21. Lim DJ, Kim JY, Baek KH, et al. Natural course of cytologically benign thyroid nodules: observation of ultrasonographic changes. Endocrinol Metab (Seoul). 2013;28(2):110-8. 
22. Ajmal S, Rapoport S, Batlle HR, Mazzaglia PJ. The Natural history of the benign thyroid nodule: what is the appropriate follow-up strategy? J Am Coll Surg. 2014.

23. Frates MC, Benson CB, Doubilet PM, et al. Prevalence and distribution of carcinoma in patients with solitary and multiple thyroid nodules on sonography. J Clin Endocrinol Metab. 2006;91(9):3411-7.

24. Gordon DL, Flisak M, Fisher SG. Changes in thyroid nodule volume caused by fine-needle aspiration: a factor complicating the interpretation of the effect of thyrotropin suppression on nodule size. J Clin Endocrinol Metab. 1999;84(12):4566-9.

25. Slowinska-Klencka D, Popowicz B, Wozniak E, Sporny S, Klencki M. The influence of fine-needle aspiration biopsy of the thyroid gland on the size of the examined nodule and its ultrasound image. Arch Med Sci. 2012;8(6): 1059-64.

26. Dralle H, Musholt TJ, Schabram J, et al. German Association of Endocrine Surgeons practice guideline for the surgical management of malignant thyroid tumors. Langenbecks Arch Surg. 2013;398(3):347-75.

Submit your next manuscript to BioMed Central and we will help you at every step:

- We accept pre-submission inquiries

- Our selector tool helps you to find the most relevant journal

- We provide round the clock customer support

- Convenient online submission

- Thorough peer review

- Inclusion in PubMed and all major indexing services

- Maximum visibility for your research

Submit your manuscript at www.biomedcentral.com/submit
Biomed Central 